\title{
COMPARAÇÃO DA COBERTURA VEGETAL NAS ÁREAS DE PRESERVAÇÃO PERMANENTE NA REPRESA DE ALAGADOS (PR), DE 1980 A 2001
}

\section{EVALUATION OF THE PROTECTED RIPARIAN AREAS AT ALAGADOS RESERVOIR, PARANÁ, SOUTHERN BRAZIL, FROM 1980 TO 2001}

\author{
José Carlos Moro', Elci Terezinha Veiga Costa ${ }^{2}$, Sandro Milanese', \\ Rosemeri Segecin Moro ${ }^{4}$ \\ 1 ABC Consultoria Ambiental, Ponta Grossa, PR \\ 2 Instituto Ambiental do Paraná - IAP, Regional Ponta Grossa, Ponta Grossa, PR \\ 3 Universidade Estadual de Ponta Grossa, Programa de Mestrado em Agronomia, \\ Campus em Uvaranas, Ponta Grossa, PR \\ 4 Autor para contato: Universidade Estadual de Ponta Grossa, Departamento de \\ Biologia Geral, Campus em Uvaranas, Ponta Grossa, PR, Brasil; (42) 3220-3742, \\ e-mail: luzmoro@uepg.br
}

Recebido para publicação em 03/08/2005

Aceito para publicação em 19/10/2005

\section{RESUMO}

Trabalhou-se na faixa de Preservação Permanente (APP) de 100 metros às margens da represa de Alagados, na região dos Campos Gerais, entre os municípios de Ponta Grossa, Castro e Carambeí, PR, com objetivo de comparar sua cobertura vegetal, em 1980 e 2001. Alagados representa uma das principais fontes de abastecimento de água da cidade de Ponta Grossa, e a ocupação de suas APPs pode acarretar danos ambientais ao manancial. Utilizou-se sensoriamento remoto e fotointerpretação para detectar alterações ao longo das APPs, com posterior digitalização e confecção de mapas georreferenciados. Observou-se que no período de duas décadas, numa área total protegida de 444 ha, ocorreram pequenos aumentos nas áreas ocupadas com edificações (2,4 ha), nas áreas reflorestadas (2,8 ha) e nas áreas em recuperação da Floresta Ombrófila Mista (19,5 ha), com expressiva ocupação de campo (80,4 ha, ou 51,3\%), e considerável aumento da área agrícola (55,7 ha, ou 322,4 \%). Não houve alterações nas áreas cortadas pela faixa de domínio da ferrovia, estradas secundárias e várzeas. No período compreendido pelo estudo, ocorreram alterações na 
legislação ambiental. A ocupação de APP determina impactos negativos como aumento da poluição, eutrofização, contaminação biológica, erosão, assoreamento e perda da diversidade biológica.

Palavras-chave: cobertura vegetal, áreas de preservação permanente, avaliação

\begin{abstract}
This work was developed in the Alagados Reservoir, in the Campos Gerais region of Paraná, in southern Brazil. It aimed to compare the land use of the protected riparian areas between 1980 and 2001, by means of remote sensing, pattern identification in aerial images and thematic map overlaying. Alagados is the main reservoir of potable water that supplies the city of Ponta Grossa (330,000 inhabits.) and its protection concerns everyone. After two decades, in the whole protected area of $444 \mathrm{ha}$, a slight increase in the constructed area (2.4 ha), in the exotic forested areas (2.8 ha) and in the natural forested areas (19.5 ha), could be observed, while the natural prairies (80.4 ha, or $51.3 \%$ ) had been reduced due to a great expansion of the cultivated area (55.7 ha, or $322.4 \%$ ), since agriculture represents the main economic activity of the region. Areas occupied by roads and wetlands had not changed. The major predictable impacts of the suppression of the riparian areas are pollution, eutrophication, biological contamination, erosion and loss of biodiversity.
\end{abstract}

Key words: land evaluation, protected riparian areas

\section{Introdução}

As formas impróprias da exploração do ambiente natural e o uso inadequado dos recursos naturais vem causando desequilíbrio e comprometimento para a geração atual, e principalmente, para as futuras.

As matas ciliares são uma das formações vegetais mais importantes para a preservação do equilíbrio da natureza, pois protegem rios, córregos e mananciais, retendo as impurezas e preservando a qualidade da água. Devido a sua importância nos diversos setores de atividades do uso do solo, sofrem as mais variadas formas de exploração.

Desde meados do século passado, enfoques às vezes conflitantes, vêm afetando visivelmente a conservação da vegetação ciliar da Represa de Alagados (Capri, 1999; Goulart, 2001; UEPG, 2002; Vergés; Milleo, 2003), com reflexos principalmente sobre o abastecimento de água da cidade de Ponta Grossa, totalmente dependente desta microbacia (Wiecheteck et al., 1999; Wiecheteck et al., 2001). Este teve como objetivo comparar a evolução e o desenvolvimento da cobertura vegetal ripária nas áreas de preservação permanente na Represa de Alagados, no período de 1980 a 2001, sob redações diferentes do Código Florestal.

\section{Fundamentação teórica}

\subsection{Vegetação ripária}

Compreende a vegetação em torno dos cursos d'água e suas nascentes, bem como margens de lagos e lagoas. Quando composta por elementos arbustivoarbóreos, inserida num contexto florestal, como ocorre no primeiro planalto paranaense, é denominada mata 
ciliar. Porém, se inserida num contexto campestre, como é comum no segundo planalto, denomina-se preferencialmente mata de galeria (Rodrigues; Leitão Filho, 2000).

Estas matas são estreitas e freqüentemente descontínuas, com características vegetacionais bem definidas por uma interação complexa de fatores definidores da paisagem, que refletem as características geológicas, geomorfológicas, climáticas, hidrológicas e hidrográficas e, portanto, as condições ecológicas locais (Rodrigues; Leitão Filho, 2000). Têm sido consideradas corredores biológicos extremamente importantes para o movimento da fauna ao longo da paisagem, assim como para a dispersão vegetal e o processo de regeneração natural.

\subsection{Mecanismos legais de proteção da zona ripária (IAP, 1999)}

O Código Florestal, estabelecido através da Lei Federal n ${ }^{\circ} 4.771$ de 1965 impôs a obrigatoriedade da Reserva Legal (RL) e das Áreas de Preservação Permanente (APPs) ${ }^{1}$ em todas as propriedades. Na região Sul, a RL compreende áreas de vegetação nativa representadas em uma ou várias parcelas, em pelo menos $20 \%$ da área total da propriedade rural, com uso permitido apenas através de técnicas de manejo que garantam a sua perpetuidade. Permite-se também o uso de espécies exóticas e/ou de valor na fruticultura quando aplicadas à pequenas propriedades rurais (até 30 ha). Pode coincidir com as APPs e com Corredores da Biodiversidade ${ }^{2}$. Restringe o uso de parte certa e localizada de cada imóvel, em caráter perpétuo e imutável, que deve ser especificada na matrícula do Registro de Imóveis.

A extensão das APPs no entorno de represas para geração de energia elétrica foi definida pela Resolução CONAMA 004/85, em seu art. $3^{\circ}$., alínea b, inciso III, em 100 (cem) metros. Este parâmetro passou a constar da Lei Federal $n^{0} 7.803 / 89$, que alterou a Lei 4771/65.
A Constituição Federal deu competência comum a todas as entidades da federação para preservar as florestas (art. 23, VII). Como conseqüência, o Estado do Paraná promulgou o Decreto Estadual n 387/99 implantando o Sistema de Manutenção, Recuperação e Proteção da Reserva Florestal Legal e Áreas de Preservação Permanente - SISLEG, integrado ao Programa de Conservação da Biodiversidade (IAP, 1999). As diretrizes básicas do SISLEG são a manutenção dos remanescentes florestais nativos; ampliação da cobertura florestal visando à conservação da biodiversidade e o uso dos recursos florestais; recuperação de zonas prioritárias para conservação através de corredores de biodiversidade.

\section{Caracterização da área em estudo}

\subsection{Física}

A bacia hidrográfica do manancial de Alagados está inserida na região dos Campos Gerais, no quadrante sudeste do Paraná, quase totalmente no Primeiro Planalto, limitada pelas coordenadas geográficas 24052' a $25^{\circ} 05^{\prime}$ ' de latitude $S$ e $49^{\circ} 46^{\prime \prime}$ a $50^{\circ} 06^{\prime}$ ' de longitude W de Greenwich, (UTM 592.000 a 624.000 e 7.226. 300 a 7.249.800), abrangendo parte dos municípios de Ponta Grossa, Castro e Carambeí (UEPG, 2002).

Alagados é a designação utilizada para nomear a área inundada pelo represamento das águas do rio Pitangui (Fig.1), por ocasião da construção de uma barragem em 1929 pela Companhia Prada de Eletricidade S/A, com a finalidade de geração de energia elétrica. Posteriormente para suprir a demanda, essa barragem teve sua altura elevada para 12 metros (Lange, 1998). Com a conseqüente formação do lago, despertou-se o interesse para ocupação de suas margens com casas de lazer na década de 40 e 50. Em 1972 a Empresa Paranaense de Energia (COPEL), assumiu a

\footnotetext{
${ }^{1}$ são florestas e demais formas de vegetação situadas em áreas elencadas no Art. 2o. do Código Florestal Brasileiro, e pelo Art. 3o. da mesma Lei, quando declaradas por ato do Poder Público.

2 são constituídos por faixas de $10 \mathrm{~km}$ ao longo dos principais rios e afluentes das diversas bacias hidrográficas do Estado do Paraná, conforme proposto no Programa "Rede da Biodiversidade” que prioriza áreas do território estadual para planejamento.
} 
geração de energia elétrica; em 1977 cede à Companhia de Saneamento do Paraná (SANEPAR), a instalação de captação para o abastecimento de água de Ponta Grossa (UEPG, 2002). Na década de 90 houve uma ocupação desordenada das margens da represa, a qual conta atualmente com mais 150 construções residenciais, considerando somente a orla sul, pertencente ao município de Ponta Grossa (Goulart, 2001).

A área drenada, na bacia do rio Jotuba, é de $133,8 \mathrm{Km}^{2}$, e na bacia do rio Pitangui é de 170,073 $\mathrm{Km}^{2}$. A área da lâmina d'água da represa é de 7,31 $\mathrm{Km}^{2}$, na cota 918,60 m. Apresenta extensão de 10,7 $\mathrm{Km}$ no trecho compreendido ente a barragem e a foz do rio Pitangui, e de 9,0 Km da mesma barragem até a foz do rio Jotuba, com larguras variando de 200 a $800 \mathrm{~m}$. Sua profundidade máxima é de $14 \mathrm{~m}$ e acumula cerca de 27,7 milhões de $\mathrm{m}^{3}$ de água, com vazão média de $9,4 \mathrm{~m}^{3} / \mathrm{s}$ (Goulart, 2001).

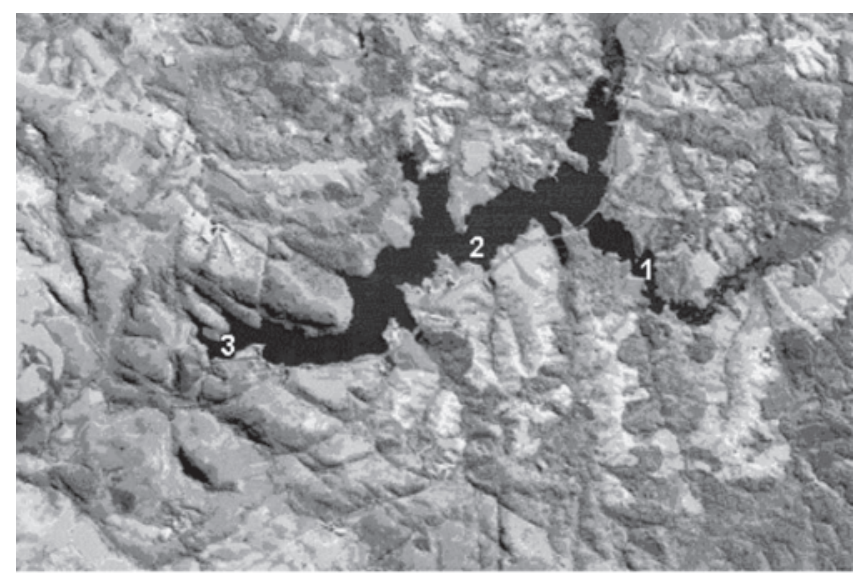

Figura 1 - Imagem de satélite da Represa Alagados, indicando: 1- início do barramento (Rio Pitangui); 2corpo da represa; 3- barragem.

\subsection{Vegetação atual}

A região da Represa de Alagados encontra-se numa área de transição entre o Primeiro e o Segundo Planaltos Paranaenses. No Primeiro Planalto a vegetação ocorrente pertence à zona fitoecológica Floresta Ombrófila Mista Montana, conforme classificação da vegetação brasileira do IBGE (VELOSO; RANGEL FILHO; LIMA, 1991). A vegetação da parte oriental do segundo planalto está incluída na zona fitoecológica Estepe Gramíneo-Lenhosa. Aárea dos Campos Gerais é considerada como de tensão ecológica, devido à existência de contatos entre tipos e encraves vegetacionais diversos (LEITE; KLEIN 1990). Pelas condições edáficas, a ocupação florestal não tem sido total, especialmente próximo à Escarpa Devoniana, em solos litólicos rasos, secos ou hidromórficos.

\subsection{1. Áreas de formação pioneira}

Várzeas são formações vegetais arbustivoarbóreas que acompanham os flancos dos rios, e que freqüentemente apresentam áreas inundáveis. O alagamento nas partes mais baixa dos rios formam as manchas de turfa onde proliferam algumas plantas bem características como o esfagno (Sphagnum recurvum), licopódios (Lycopodium carolinianum) e selaginela (Selaginella sulcata) e as pequenas insetívoras Utricularia, Gelinsea e Drosera. Na vegetação arbórea de várzea é comum a corticeira-do-banhado (Erythrina crista-galli). As ervas presentes neste solos aluviais são a flor das almas (Senecio bonariensis), cruz-de-malta (Ludwigia sericea, L. peruviana), estrela-d’água (Nymphoides indica), aguapé (Pontederia), língua-de-vaca (Rumex), ciperáceas várias e lobélias (MORO, 2001).

Em locais planos, de encharcamento, de correnteza muito lenta ou mesmo estagnada ligados a uma várzea ou pequeno regato encontram-se os brejos. $\mathrm{O}$ solo hidromórfico suporta uma vegetação característica de ervas muito altas ciperáceas, juncáceas, eriocauláceas, compostas e verbenáceas.

Nas matas ciliares de várzeas costuma ocorrer, nos diques sedimentares, branquinho (Sebastiania klotzschiana), bugreiro (Lithraea molleoides), juvevê (Zanthoxylum rhoifolia), laranjeira-do-mato (Actinostemon concolor), Cambuí-do-brejo (Myrciaria tenella) e embira (Daphnopsis beta). Nas matas de inundação predominam o vacum (Alophyllus edulis) e a canela-fedida (Nectandra grandiflora). As lianas podem ser abundantes, dificultando a visualização do dossel. Nas matas alteradas, podem ser dominantes as moitas espinhosas de maricá (Acacia) (UEPG, 2002).

\subsection{2. Áreas campestres}

Os campos úmidos, formados por afloramentos do lençol freático nas quebras de relevo e nos solos litólicos mal drenados são marcados pela presença de 
compostas, ciperáceas, sempre-vivas (Eriocaulon, Paepalanthus, Syngonanthus), botão-de-ouro (Xyris) e polígalas. Essas ervas são poupadas do fogo devido à umidade constante do terreno (MORO, 2001).

Nos campos secos rochosos florescem espécies herbáceas ou arbustivas lenhosas com característica xerófitas. É comum nestas plantas a presença de óleos essenciais, que conferem odor ou sabor fortes, e de tecidos que acumulam água. Numerosas plantas campestres apresentam órgãos subterrâneos espessados, como bulbos, rizomas e xilopódios.

Os campos secos, embora fisionomicamente uniformes possuem grande diversidade de ervas rasteiras, como verbenáceas, labiadas, compostas, rubiáceas, malpiguiáceas, malváceas, melastomatáceas e leguminosas.

Os campos antrópicos apresentam em geral gramíneas prostradas ou cespitosas baixas, como Paspalum e Axonopus, de crescimento estival. Com a diminuição do pastoreio aumenta a quantidade de gramíneas cespitosas altas, como Andropogon (macega), Aristida e Erianthus (sapê), que acumula biomassa de alta inflamabilidade. O capim barba-de-bode (Aristida jubata) surge preferencialmente nos campos sujeitos a erosão, alterados pela agricultura ou pelo pisoteio do gado.

Nos campos rochosos, ou de elementos desagregados (campos pedregosos), a vegetação desenvolvese sobre uma tênue capa de solo, suportando vistosas amarilidáceas, bromélias e iridáceas permeadas por ciperáceas, algumas gramíneas e pteridófitas. Desenvolvem-se neste ambiente a maioria das espécies endêmicas da região, como a bromélia Tillandsia crocata e o notocacto Parodia ottonis var.villa-velhensis. As fendas costumam ser colonizadas por ericácias, melastomatáceas e euforbiáceas. Sobressai-se a orquídeas Epidendron ellipticum e a rainha-do-abismo, Sinningia canescens. O capim colchão é a gramínea mais expressiva.

Nos paredões rochosos de arenito, expostos ao sol, ocorrem bromélias como Tillandsia crocata, T. lorentziana e T. stricta, e o cipó-de-São João (Pyrostegia venusta) (UEPG, 2002).

\subsubsection{Formações florestais}

Não há identificação de nenhum agrupamento clímax primário, exceto nos profundos cânions inacessíveis a noroeste da Represa. Os núcleos de capões, ainda que preservados, se ajustam à categoria de vegetação secundária. Têm origem em pequenos aglomerados arbustivos nos campos, e são distintos das plantas herbáceas ao seu redor. Formam, com freqüência, manchas de mata quase circulares nas pequenas depressões ou cabeceiras de nascentes, onde o solo é mais profundo, com maior acúmulo de detritos orgânicos. São formados por pequeno número de arbustos e arvoretas heliófitas vigorosas, como o branquinho (Sebastiania klotzschiana), bugreiro (Lithraea molleoides), copororoca (Myrsine umbellata), guaçatonga (Casearia sylvestris), congonha (Ilex), cambuís e guamirins. Quando acompanhando nascentes e cursos d'água é comum aroeira-vermelha (Schinus terebinthifolius), casca-de-anta (Drymis brasiliensis), embira (Daphnopsis racemosa) e espinheira-santa (Maytenus ilicifolia). Trepadeiras podem ser freqüentes nestes locais mais úmidos, como a criciúma (Chusquea ramosissima), guaco (Mikania cordifolia), maracujá (Passiflora), além de bignoniáceas, malpiguiáceas, sapindáceas e convolvuláceas.

Nas clareiras abertas pela retirada da madeira, forma-se uma capoeira com vassouras, juvevê, guaçatonga e sucará (Xylosma pseudosalzmannii), canela-guaicá (Ocotea puberula), carvalho (Roupala brasiliensis), samambaia-das-taperas e carobas ( $\mathrm{Ja}$ caranda). Nas áreas mais impactadas percebe-se as folhagens claras do vassourão-branco (Piptocarpha angustifolia), bracatinga (Mimosa scabrella) e vassourão-preto (Vernonia discolor).

O estrato epifítico é composto geralmente por pequenas orquídeas e samambaias, cactos, bromélias, gesneriáceas, aráceas e piperáceas. Já o extrato herbáceo é considerado pobre formado pelas gramíneas rasteiras pastinho-do-mato (Pseudochinolaena polystachya) e grama-tapete-de-folha-larga (Axonopus compressus), trapoerabas e nos locais mais úmidos, samambaias terrícolas.

A fase inicial de recolonização do solo é constituída pela capoeirinha, onde predominam ervas e arbustos, surgindo vassourais (Baccharis), mimosas e samambaia-das-taperas (Pteridium arachnoideum). Devido ao sombreamento, as espécies pioneiras da capoeirinha promovem condições microclimáticas propícias ao surgimento da capoeira. Nesta fase ar- 
bustivo-arbórea, os vassourais começam a ser substituídos por arvoretas de 5-6 m, num só estrato arbóreo, sem epífitas. Podem predominar cuvitingas (Solanum erianthum), jacatirão (Miconia), capixinguis (Croton celtidifolius) e uvaranas (Cordyline dracaenoides).

O capoeirão surge já na fase mais adiantada da sucessão arbórea, com predominância de árvores de copas amplas e altura de 10-15m, com definição de um segundo estrato arbóreo (sub-bosque) e instalação de epífitas e trepadeiras, sendo formado por aroeiras (Schinus therebenthifolius), pata-de-vaca (Bauhinia forficata), mamica-de-porca (Zanthoxyllum rhoifolia) e maria-pretinha (Solanum americanum). A fase final de substituição da floresta original compõe a floresta secundária.

Existem dois tipos de atividade silvicultural no entorno da represa de Alagados: pequenas áreas de eucalipto, utilizadas como quebra-vento em décadas anteriores e atualmente apenas para obtenção de dormentes para a ferrovia; e áreas de Pinus. Os reflorestamentos com bracatinga são menos comuns, mas estão presentes na região.

\section{Metodologia}

A análise da dinâmica da alteração de uso e ocupação do solo ao longo da faixa de PP da Represa de Alagados, seguiu as seguintes etapas:

a) Delimitação das APPs, conforme indicadas pela legislação atual, nas imagens aéreas de 1980 (ITCF) e de 2001 (Engefoto). Em 1980, não havia a obrigatoriedade da faixa de preservação de 100 metros, em vigor a partir de 1989, porém para efeitos de comparação, optou-se por analisar a ocupação de 1980 nesta mesma faixa.

b) Fotointerpretação das imagens aéreas, utilizando-se estereoscopia, definindo-se o uso e ocupação do solo em junho de 1980 e abril de 2001.

c) Mapeamento Georeferenciado e obtenção de pontos de apoio, em campo, ao longo do modelo aerofotogramétrico (base topográfica 1980/2001), com GPS Leica GS20 PDM de precisão sub-métrica: 30 a $50 \mathrm{~cm}$ e precisão milimétrica: $10 \mathrm{~mm}+2 \mathrm{ppm}$.

d) Digitalização e confecção de mapas georefe- renciados, em escala 1:15.000; Datum SAD 69, com coordenadas UTM, utilizando- se o software AUTO CAD/2000 e o software GIS DataPRO .

e) Comparação e análise das informações obtidas com o cruzamento dos mapeamentos georeferenciados 1980 e 2001.

Os elementos fotointerpretados observados são:

a) Floresta Ombrófila Mista - em diversos estágios sucessionais, na forma de matas ciliares em torno dos tributários e suas nascentes, bem como margens da represa.

b) Estepe Gramíneo Lenhosa - na forma de campos secos, campos antrópicos e campos rochosos.

c) Agricultura - áreas plantadas com culturas temporárias, mais as áreas de pastagens plantadas.

d) Várzeas - áreas inundáveis.

e) Silvicultura - monoculturas florestais com espécies exóticas.

f) Edificações - barragem, casa de máquinas, casas de veraneio, sedes de propriedades rurais e clubes, galpões, e outros.

g) Estradas - vias de acessos às áreas de ocupação; estradas de ligação entre localidades.

h) Ferrovia - área da faixa de domínio da via ferroviária.

\section{Resultados e discussão}

A Tabela 1 mostra a dinâmica de alterações do uso e ocupação do solo das APPs nos dois períodos distintos, com um intervalo de 21 anos.

Percebe-se que, da área total de 444 ha abrangida atualmente pela APP, houve aumento das áreas ocupadas com benfeitorias de veraneio (2,4 ha), numa evolução de 23,8\%.

Como já apontado em estudos anteriores na bacia (UEPG, 2002), nas APPs também foi observada expansão nas áreas ocupadas pela Floresta Ombrófila Mista em recuperação (19,5 ha), num aumento correspondente a 11,4 \% em relação à área anterior. Isto se deve, provavelmente, ao fato de serem áreas que se adequaram à mudança da legislação em 1989, ampliando a faixa de PP em represas. Após o abandono de uso por quase duas décadas, recuperaram-se dos 
estágios iniciais de capoeirinha ou capoeira.

Houve aumento considerável da área agrícola, que representa a principal fonte de renda na bacia, em 55,7 ha, ou seja, 322,4\%. Nas áreas reflorestadas, houve significativo aumento de 57,2\% (2,8 ha), refletindo a retomada do plantio de Pinus após duas décadas de estagnação. A utilização deste, sem o devido controle de irradiação de sementes, é prejudicial ao equilíbrio ecológico das comunidades campestres da bacia, especialmente aos campos rochosos (ZILLER, 2000). Como não houve decréscimo nas áreas de floresta nativa, fica evidente que esta expansão ocorreu às expensas das áreas de Savana Gramíneo Lenhosa, que efetivamente diminuíram $51,3 \%$ (80,4 ha).

Tabela 1 - Variação do uso e ocupação do solo nas Áreas de Preservação Permanente na Represa de Alagados, PR, em junho/ 1980 e abril/2001.

\begin{tabular}{|c|c|c|c|c|}
\hline $\begin{array}{c}\text { Classes de uso e } \\
\text { ocupação do solo }\end{array}$ & $\begin{array}{c}\text { Área em } \\
\text { junho/1980 (ha) }\end{array}$ & $\begin{array}{c}\text { Área em abril/2001 } \\
\text { (ha) }\end{array}$ & $\begin{array}{c}\text { \% } \\
\text { Aumento }\end{array}$ & $\begin{array}{c}\text { \% } \\
\text { Recuo }\end{array}$ \\
\hline $\begin{array}{c}\text { Edificações } \\
\text { Estepe Gramíneo }\end{array}$ & 10,1 & 12,5 & 23,8 & - \\
\hline $\begin{array}{c}\text { Lenhosa } \\
\text { Floresta Ombrófila }\end{array}$ & 156,8 & 76,4 & - & 51,3 \\
\hline Mista & 170,5 & 190,1 & 11,4 & - \\
\hline Agricultura & 17,3 & 72,9 & 322,4 & - \\
\hline Silvicultura & 4,8 & 7,6 & 57,2 & - \\
\hline Várzeas & 48,8 & 48,8 & - & - \\
\hline Estradas & 2,9 & 2,9 & - & - \\
\hline Ferrovia & 33,2 & 33,2 & - & - \\
\hline TOTAL & 444,4 & 444,4 & - & - \\
\hline
\end{tabular}

Isto pode ser interpretado como um falso entendimento das áreas de PP como mecanismos de proteção de mata ciliar apenas, e não de toda e qualquer vegetação ripária, inclusive campestre e alagável. Estáse infringindo a Lei de Crimes Ambientais e deve-se, com a maior brevidade, iniciar a recuperação das APPs em termos de sua vegetação original (no caso, campo).

Não houve alterações nas áreas cortadas pela faixa de domínio da ferrovia, estradas secundárias e várzeas.

\section{Considerações finais}

O uso de imagens aéreas para coletar e registrar informações é uma das mais importantes contribuições para o planejamento de uso e ocupação do solo. Proporciona bases para o cuidadoso planejamento de uma área, com uma disponibilidade de detalhes que, de outro modo, só seriam obtidos através de métodos convencionais de levantamento de campo, os quais são ao mesmo tempo, muito dispendiosos e demorados.

Através da análise da evolução da cobertura vegetal nas APPs da Represa de Alagados nos últimos 20 anos, percebe-se a intensa pressão econômica da agricultura sobre as áreas naturais de campo. $\mathrm{O}$ aumento da área agrícola, com as perspectivas de aumento de erosão e conseqüente assoreamento da represa, aliado ao enriquecimento das águas por nutrientes (eutrofização), leva à excessiva proliferação de algas e perda da qualidade da água. A ocupação antrópica, com casas de veraneio às margens da represa, também pode propiciar maiores probabilidades de eutrofização, pela falta de saneamento básico satisfatório.

O estabelecimento de espécies exóticas nas APPs, embora autorizado, coloca em risco a integridade dos biomas nativos, especialmente o campestre. Ainda que a legislação permita o estabelecimento de 
espécies florestais exóticas em áreas de PP, sugere-se que os proprietários sejam dissuadidos da idéia pela oferta de mudas de essências florestais nativas, mais adequadas a planos de recuperação ambiental.

Pode-se assumir como impacto positivo a manutenção das áreas de várzea em níveis similares aos de 20 anos atrás, o que demonstra não estar havendo um expressivo progresso no assoreamento da represa.

\section{REFERÊNCIAS}

1. CAPRI, L. Diagnóstico preliminar das irregularidades ambientais decorrentes da ação antrópica praticadas na Represa de Alagados, Ponta Grossa, PR. Ponta Grossa, 1999. Monografia (Especialização em Geografia Urbana e Análise Ambiental) Universidade Estadual de Ponta Grossa. 78p.

2. GOULART, C.F. Diagnóstico e zoneamento da Represa do Alagados. Ponta Grossa, 2001. Monografia (Especialização em Gestão Ambiental) - NUCLEAM/UEPG. 51p.

3. IAP. SISLEG: Sistema Estadual de Manutenção e Recuperação de Reserva Florestal legal. Decreto N ${ }^{\circ}$ 387/99.

4. LANGE, F.L.P. Os Campos Gerais e sua princesa. Curitiba: COPEL, 1998.

5. LEITE, P.F.; KLEIN, R.M. Vegetação. In: IBGE. Geografia do Brasil. Rio de Janeiro, 1990. v.2. Região Sul. p.113-150.

6. MORO, R. S. A vegetação dos Campos Gerais da Escarpa Devoniana. In: DITZEL, C.H. M.; SAHR, C.L. Espaço e cultura:
Ponta Grossa e os Campos Gerais. Ponta Grossa: Ed. UEPG, 2001.p.481-503.

7. RODRIGUES, R.R.; LEITÃO FILHO, H. de F. (Eds.) Matas ciliares: Conservação e recuperação. São Paulo: EDUSP/ FAPESP, 2000. cap.6.

8. UEPG. NUCLEAM. Bacia hidrográfica do manancial Alagados. Ponta Grossa, 2002. (Relatório técnico) - CD-ROM.

9. VELOSO, H.P.; RANGEL FILHO, A.L.; LIMA, J.C.A. Classificação da vegetação brasileira, adaptada a um sistema universal. IBGE: Rio de Janeiro, 1991. 123p.

10. VERGÉS, D.; MILLEO, R.D. de S. A relação da atividade agrícola do entorno da Represa de Alagados com o processo de eutrofização cultural. Ponta Grossa, 2003. Monografia (Especialização em Gestão Ambiental) - NUCLEAM/ UEPG.

11. WIECHETECK, G.K.; BUSCH, O.M.S.; HINSCHING, M.A. de $\mathrm{O}$. Análise dos impactos ambientais sobre a qualidade de água no manancial do Rio Pitangui (Ponta Grossa - PR): um estudo de caso. Ponta Grossa: UEPG, 2001. (Relatório de Pesquisa).

12. WIECHETECK, G.K.; MORO, R.S.; SCHMITT, J.; SALDANHA, J. Biomonitoramento da qualidade de água de abastecimento de Ponta Grossa, Paraná. In: JORNADA CIENTÍFICA DE PESQUISA SOCIAL. (1: 1999: Ponta Grossa). Anais ... (disquete)

13. ZILLER, S.R. A estepe gramíneo-lenhosa no segundo planalto do Paraná: diagnóstico ambiental com enfoque à contaminação biológica. Curitiba, 2000. Tese (Doutorado em Engenharia Florestal) - Universidade Federal do Paraná (UFPR). 